\title{
Pheochromocytoma-induced inverted Takotsubo cardiomyopathy: A case of patient resuscitation with extracorporeal life support
}

\author{
Rachid Zegdi, MD PhD, ${ }^{a, b}$ Caroline Parisot, MD, ${ }^{a}$ Ghassan Sleilaty, MD, ${ }^{a}$ Alain Deloche, MD, ${ }^{a, b}$ \\ and Jean-Noël Fabiani, MD, ${ }^{a, b}$ Paris, France
}

Video clip is available online.

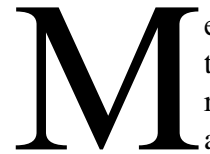

echanical circulatory support for pheochromocytoma-induced cardiomyopathy has been reported rarely. ${ }^{1}$ We describe the case of a patient with an atypical form of pheochromocytoma-induced cardiogenic shock who was successfully managed with extracorporeal life support (ECLS).

\section{Clinical Summary}

A 51-year-old woman with a medical history suggestive of Crohn disease and newly diagnosed hypertension had acute respiratory

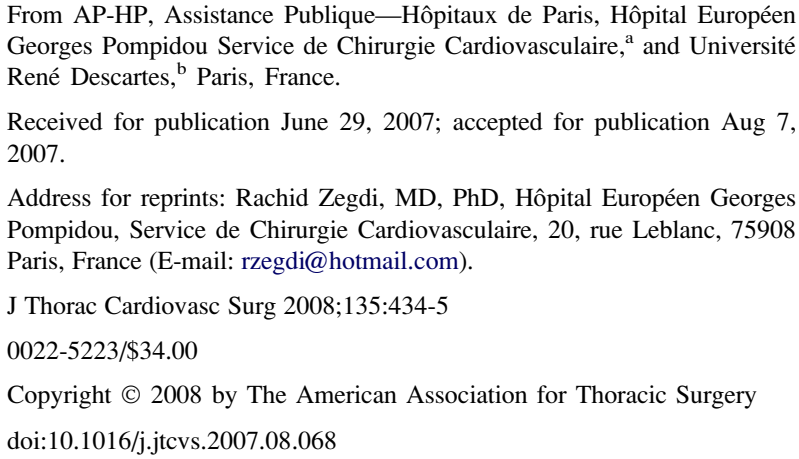

From AP-HP, Assistance Publique-Hôpitaux de Paris, Hôpital Européen Georges Pompidou Service de Chirurgie Cardiovasculaire, ${ }^{a}$ and Université René Descartes, ${ }^{\mathrm{b}}$ Paris, France.

Received for publication June 29, 2007; accepted for publication Aug 7, 2007.

Address for reprints: Rachid Zegdi, MD, PhD, Hôpital Européen Georges Pompidou, Service de Chirurgie Cardiovasculaire, 20, rue Leblanc, 75908 Paris, France (E-mail: rzegdi@hotmail.com).

J Thorac Cardiovasc Surg 2008;135:434-5

$0022-5223 / \$ 34.00$

Copyright (C) 2008 by The American Association for Thoracic Surgery doi:10.1016/j.jtcvs.2007.08.068

failure 2 hours after mastectomy for breast cancer. Clinically, the patient harbored pulmonary edema, tachycardia, and high blood pressure. Electrocardiography revealed ST-segment depression in inferior and lateral leads, and initial troponin I blood level was increased to $3 \mu \mathrm{g} / \mathrm{L}$.

On admission to the intensive care unit, the patient had cardiogenic shock with metabolic acidosis $(\mathrm{pH}=7.14)$, acute renal failure (creatinine level $=184 \mu \mathrm{mol} / \mathrm{L})$, and increased troponin I level (27 $\mu \mathrm{g} / \mathrm{L}$; reference range $<0.1 \mu \mathrm{g} / \mathrm{L}$ ). Echocardiography revealed severe global left ventricular hypokinesia (ejection fraction $[\mathrm{EF}]<$ $30 \%$ ) with no pericardial effusion. Severe cardiorespiratory failure necessitated tracheal intubation and mechanical ventilation. Emergency coronary angiogram was performed to assess the integrity of the coronary vascular bed. On the way to the catheterization laboratory, cardiac arrest occurred owing to electromechanical dissociation. The patient recovered rapidly with intravenous administration of epinephrine. A coronary angiogram revealed fully patent coronary arteries (Figure 1). However, ventriculography showed dilation and akinesis of the basal and midventricular segments of the heart, whereas the apex was hyperkinetic (Video 1). Global left ventricular EF was less than $30 \%$.

The patient's hemodynamics kept worsening despite incremental doses of dobutamine, up to $20 \mu \mathrm{g} \cdot \mathrm{kg}^{-1} \cdot \mathrm{min}^{-1}$. Several episodes of electromechanical dissociation occurred. Femorofemoral ECLS was rapidly initiated while the patient was receiving cardiac massage.

The clinical status improved drastically with circulatory assistance. On day 0, EF was less than $5 \%$ and increased to $50 \%$ on day 5 (Figure 2). ECLS was removed the day after. On day 7, EF was $72 \%$ without any inotropic support. Hemodynamic improvement was paralleled by regression of the pulmonary edema and the acute renal failure, allowing extubation on day 8 .
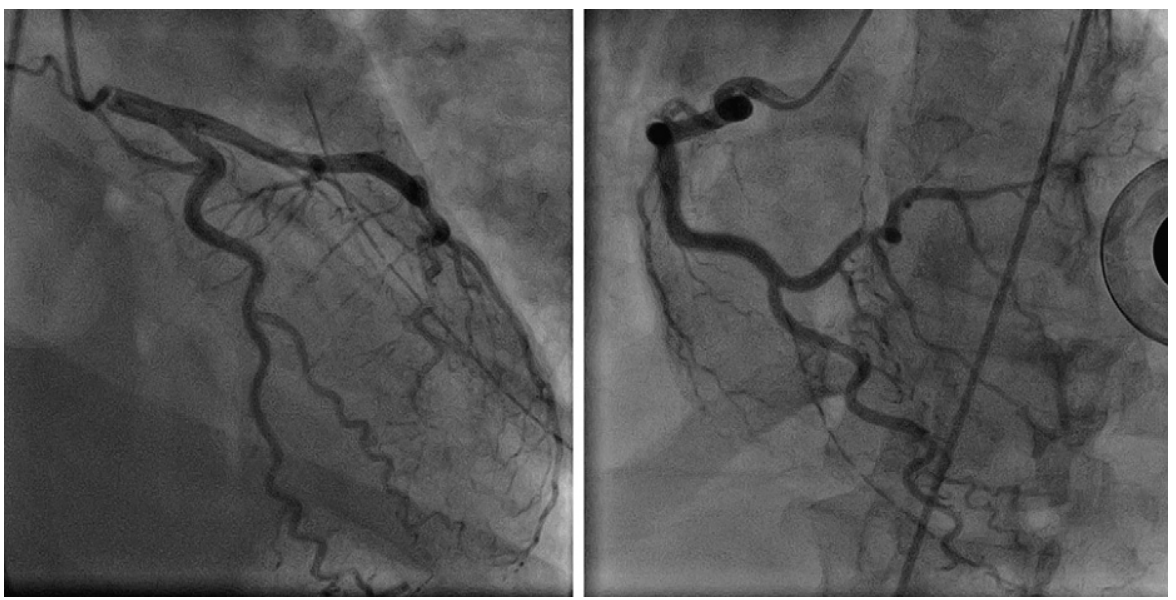

Figure 1. Coronary angiogram showing absence of luminal stenosis in the left (left) and right (right) coronary arteries. 

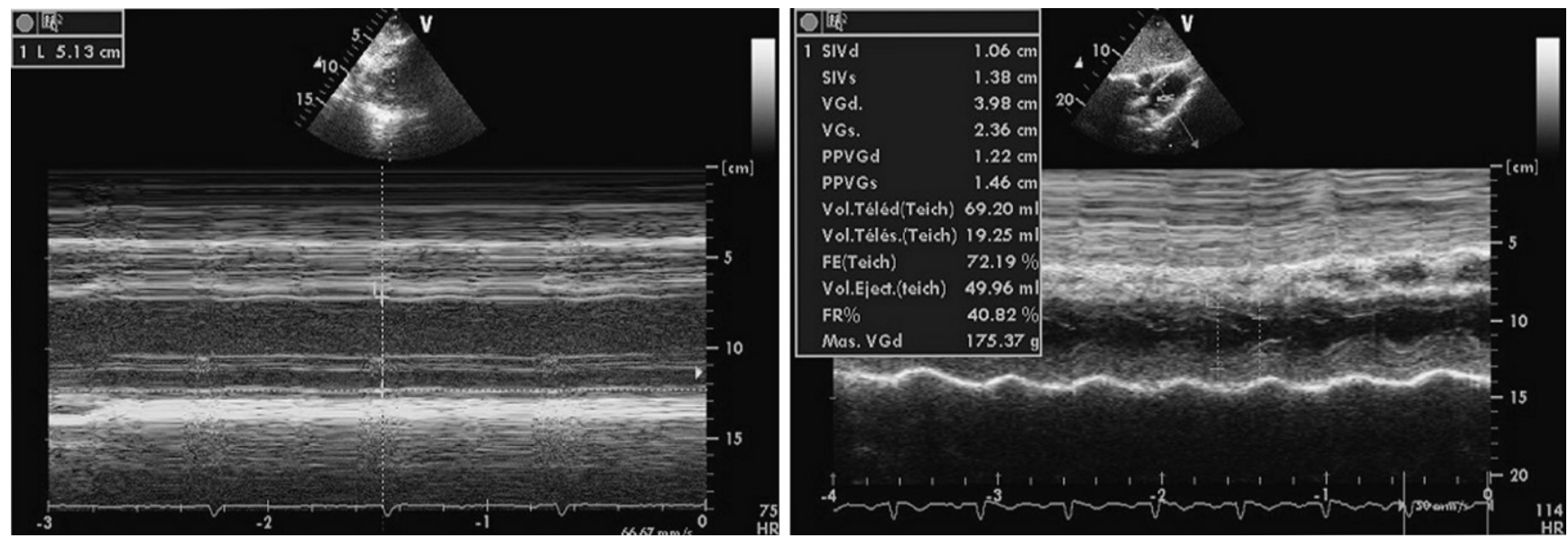

Figure 2. Left ventricular function evolution in this patient with severe inverted Takotsubo cardiomyopathy. Ejection fraction increased from less than $5 \%$ on day 0 (left) to $72 \%$ on day 7 (right).

The medical history of newly developed hypertension and reversible severe myocardial dysfunction were suggestive of pheochromocytoma-induced cardiomyopathy. Levels of urinary metanephrine (on day 10) were higher than normal. Abdominal computed tomographic scan revealed a mass occupying the right adrenal gland. One month later, the patient underwent celioscopic right suprarenalectomy. Pheochromocytoma was confirmed on histologic analysis.

\section{Discussion}

Takotsubo cardiomyopathy syndrome is being more frequently recognized. ${ }^{2}$ It affects mainly women in the postmenopausal period. It consists in an acute coronary syndrome with angiographically normal coronary vessels and reversible left ventricular wall motion abnormalities. Typically, the left ventricular apex is dyskinetic (apical ballooning) whereas the basal portion is hyperkinetic. However, variant forms sparing the apex have been recently reported. ${ }^{3}$

The cardiac surgeon is faced with Takotsubo cardiomyopathy or its variants mainly when cardiogenic shock develops in these settings. Incidence of cardiogenic shock after Takotsubo cardiomyopathy reached $15 \%$ in a recent large series. ${ }^{4}$ Anecdotal descriptions of left ventricular apical rupture or thrombosis in this syndrome were also reported. ${ }^{2}$ Besides inotropic support, circulatory assistance may be required as in the present case. Reversibility is a major characteristic of this syndrome. Left ventricular recovery, within a week, was particularly impressive in our patient. Takotsubo cardiomyopathy seems to have a better prognosis than myocardial infarction and does not usually recur. ${ }^{2}$
Another major point in the care of patients with Takotsubo cardiomyopathy is the search for a curable cause. Usually, the syndrome is "idiopathic," and a precipitating factor (an emotional or a physical stress) can be often individualized. Exceptional cases of pheochromocytoma-induced Takotsubo cardiomyopathy have been reported, ${ }^{5}$ but the pathogenesis of the syndrome is unknown, albeit this association favors a cardiotoxic effect of catecholamines.

In conclusion, cardiac surgeons should be aware of this recently recognized syndrome and particularly of its reversal, even in the most clinically severe forms, as reported here.

\section{References}

1. Takagi S, Miyazaki S, Fujii T, Daikoku S, Sutani Y, Morii I, et al. Dexamethasone-induced cardiogenic shock rescued by percutaneous cardiopulmonary support (PCPS) in a patient with pheochromocytoma. Jpn Circ J. 2000;64:785-8.

2. Gianni M, Dentali F, Grandi AM, Sumner G, Hiralal R, Lonn E. Apical ballooning syndrome or Takotsubo cardiomyopathy: a systematic review. Eur Heart J. 2006;27:1523-9.

3. Haghi D, Papavassiliu T, Flüchter S, Kaden JJ, Pörner T, Borggrefe M, et al. Variant form of the acute apical ballooning syndrome (Takotsubo cardiomyopathy): observations on a novel entity. Heart. 2006;92: 392-4.

4. Tsuchihashi K, Ueshima K, Uchida T, Oh-mura N, Kimura K, Owa M, et al. Transient left ventricular apical ballooning without coronary artery stenosis: a novel heart syndrome mimicking acute myocardial infarction. J Am Coll Cardiol. 2001;38:11-8.

5. Sanchez-Recalde A, Costero O, Olivier JM, Iborra C, Ruiz E, Sobrino JA. Pheochromocytoma-related cardiomyopathy. Inverted Takotsubo contractile pattern. Circulation. 2006;113:e738-9. 